\title{
Dominant Factors Influencing the Concentrations of Particulate Matters inside Train Carriages Traveling in Different Environments in the Taipei Mass Rapid Transit System
}

\author{
Yu-Hsiang Cheng ${ }^{1,2 *}$, Xuan-Huy Ninh ${ }^{1}$, Shu-Lun Yeh $^{1}$ \\ ${ }^{1}$ Department of Safety, Health and Environmental Engineering, Ming Chi University of Technology, New Taipei 24301, \\ Taiwan \\ ${ }^{2}$ Chronic Diseases and Health Promotion Research Center, Chang Gung University of Science and Technology, Chiayi \\ 61363, Taiwan
}

\begin{abstract}
Air quality inside metro systems is a critical issue for commuters and metro employees because of the considerable time they spend traveling or working in such systems. This study measured the $\mathrm{PM}_{10}, \mathrm{PM}_{2.5}$, particle number $(\mathrm{PN})$, and $\mathrm{CO}_{2}$ levels and particle mass size distributions inside operating trains to reveal the factors influencing the concentrations and size distributions of particulate matter (PM) inside metro train carriages traveling in different environments. The measurement results demonstrated that the $\mathrm{CO}_{2}$ level was associated with ridership and that the PM levels and particle mass size distributions were highly affected by the immediate surroundings of the train, such as whether it was journeying through underground tunnels or on ground-level tracks as well as its direction of travel. Furthermore, the particle mass size distributions inside the metro train carriages exhibited a clear triple-mode pattern, whereas those for the ground-level and underground routes differed considerably due to different particle sources.
\end{abstract}

Keywords: Train carriage; Particle mass size distribution; Journey; Underground tunnel.

\section{INTRODUCTION}

Metro systems constitute a major public transportation mode and typically serve billions of commuters annually in metropolitan areas worldwide because of their advantages, such as environmental friendliness, efficiency, low emission, and high capacity, as compared with other transportation modes. However, the air quality inside metro systems is a critical issue for commuters because they usually spend considerable time, occasionally up to $1-2 \mathrm{~h}$ a day, either on platforms or inside trains, especially inside train carriages.

At the start of the 1990s, Chan et al. (1991) conducted an extensive study of commuter exposure in the subway system in Boston. After this study and more than a decade of research, different air pollutants and their levels have been measured in many metro systems worldwide (Nieuwenhuijsen et al., 2007). Most of these studies have concentrated on the levels of suspended particulate matter (PM) and its elemental compositions (Salma et al., 2009; Abbasi et al., 2013; Martins et al., 2015) because suspended

\footnotetext{
* Corresponding author.

Tel.: +886-2-29089899; Fax: +886-2-29082201

E-mail address: yhcheng@mail.mcut.edu.tw
}

PM in a metro system strongly affects health (Karlsson et al., 2006; Bachoual et al., 2007; Karlsson et al., 2008; Steenhof et al., 2011).

According to these previous studies, the widely varying PM concentrations on metro platforms and inside train carriages in different metro systems depend on a complex interplay of factors such as differences in the length and design of stations and tunnels, system age, wheel and railtrack materials and braking mechanisms, train speed and frequency, passenger densities, ventilation and air conditioning systems, and cleaning frequency (Salma et al., 2007; Moreno et al., 2014; Woo et al., 2018). On platforms and inside train carriages, the average $\mathrm{PM}_{10}$ concentrations are usually in the ranges of 38-457 and 16-312 $\mu \mathrm{g} \mathrm{m}^{-3}$, respectively, and the $\mathrm{PM}_{2.5}$ concentrations are 19-352 and 14-247 $\mathrm{\mu g} \mathrm{m}^{-3}$, respectively (Cheng et al., 2012; Abbasi et al., 2013; Cartenì et al., 2015; Martins et al., 2015). The primary element in metro $\mathrm{PM}$ is $\mathrm{Fe}$, and other elements are $\mathrm{Si}, \mathrm{Mn}, \mathrm{Cr}, \mathrm{Cu}, \mathrm{Ca}$, and $\mathrm{K}$ (Querol et al., 2012; Cusack et al., 2015; Moreno et al., 2015; Chen et al., 2017).

Although levels of $\mathrm{PM}_{10}, \mathrm{PM}_{2.5}$, or particle number (PN) have been measured on platforms and inside train carriages in many metro systems, information related to the characteristics of particle size distributions in metro systems is limited (Salma et al., 2009; Abbasi et al., 2013). Cheng and Yan (2011) investigated the particle mass size 
distributions at three metro stations, and they reported the size distribution patterns to be considerably different at ground and in underground stations. The particle mass size distributions in the underground ticket hall and platform exhibited a two-mode pattern: an accumulation mode (approximately $0.4 \mu \mathrm{m}$ ) and a coarse mode $(>15 \mu \mathrm{m})$. A large fraction of coarse PM in the underground ticket hall and platform had been resuspended by the movement of large numbers of commuters, and fine PM was likely transferred from its source outside the station. Particle size not only influences the severity of adverse health effects but also conveys information on factors contributing to particle formation and generation. Therefore, to understand PM generation mechanisms, investigating the particle size distributions in underground metro systems is necessary.

The Taipei Mass Rapid Transit (MRT) system comprises five metro lines stretching $131.1 \mathrm{~km}$, linking 117 stations, carrying, on average, approximately 2.1 million commuters per day, and making nearly 740 million journeys per year (TRTC, 2017). It has become one of the largest metro systems in the world; however, concerns have been raised over whether the suspended PM can pose a health risk to commuters and metro employees. Therefore, the objectives of this study were to measure the $\mathrm{PM}_{10}, \mathrm{PM}_{2.5}$, and $\mathrm{PN}$ levels and particle mass size distributions inside operating trains to reveal the factors influencing the concentrations and size distributions of PM inside metro train carriages traveling in different environments, such as their journey in underground tunnels, on ground-level tracks, and in different travel directions. In this study, the $\mathrm{CO}_{2}$ levels were also measured because it is a common air quality index in indoor environments. Based on field measurement results, some methods are proposed for improving air quality in the Taipei MRT system when it continues to expand in the future.

\section{METHODS}

\section{Taipei MRT System}

Fig. 1 shows a map of the Taipei MRT system. Currently, this system comprises five routes - namely the Brown Line (BR), Red Line (R), Green Line (G), Orange Line (O), and Blue Line (BL) - and uses two types of train cars depending on the transportation capacity. Except for the BR, all metro lines are designed as heavy-capacity. A heavy-capacity train consists of two 3-car electric multiple unit (EMU) sets with a total of six cars, which are interconnected (Figs. 2(a)2(b)). Each car of the heavy-capacity train is approximately $23.5 \mathrm{~m}$ long, $3.2 \mathrm{~m}$ wide, and $3.6 \mathrm{~m}$ high, and it has four doors on each side. A heavy-capacity train has steel wheels and runs on steel rails. Despite the train being computer controlled, it is still monitored by an onboard operator. The $\mathrm{BR}$ is a medium-capacity metro line. Each train consists of two 2-car EMU sets, with a total of four cars; each car is separate and not interconnected (Figs. 2(c) and 2(d)). Each car of the medium-capacity train is approximately $13.9 \mathrm{~m}$ long, $2.5 \mathrm{~m}$ wide, and $3.7 \mathrm{~m}$ high, and there are two doors on each side of the car. Unlike heavy-capacity trains, medium-capacity trains use rubber tires and are operated remotely by the system control center without an onboard operator. In the Taipei MRT system, all train carriages are equipped with air conditioners. The temperature difference between the inside and outside of the train carriage was kept less than $10^{\circ} \mathrm{C}$ to avoid encountering the thermal shock problem. Moreover, the relative humidity inside the train carriage was kept between $30 \%$ and $70 \%$. The air supply inside the train carriage was made up of $80-90 \%$ recirculated air and $10-20 \%$ of fresh air.

In this study, the routes in the Taipei MRT system were divided into two groups based on their operating mode: ground-level route and underground route. Table 1 presents a summary of the operating mode, travel time, length, and number of stations for the seven arranged routes in this study. The ground-level route comprises BR and $R(G)$, whereas the underground route comprises $R$ (UG), G, $\mathrm{O}(\mathrm{A}), \mathrm{O}(\mathrm{B})$, and BL.

BR almost operates on the ground level, except for a small section between Songshan Airport Station (BR13) and Dazhi Station (BR14). However, the length of this small underground section is only approximately $3.1 \mathrm{~km}$. Thus, BR was considered as a ground-level route in this study. $\mathrm{R}$ is the only route among these heavy-capacity metro lines that has underground and ground-level sections in the Taipei MRT system. The underground section, R (UG), stretches from Xiangshan Station (R02) to Minquan W. Rd Station (R13), whereas the ground-level section, R (G), stretches from Yuanshan Station (R14) to Tamsui Station (R28). Additionally, O currently runs on two separate routes: $\mathrm{O}$ (A) from Nanshijiao Station (O01) to Huilong Station $(\mathrm{O} 21)$ and $\mathrm{O}(\mathrm{B})$ from Nanshijiao Station (O01) to Luzhou Station (O54). On this route, the train runs on the same section between Nanshijiao Station (O01) and Daqiaotou Station (O12).

The operating time of the Taipei MRT system is from 06:00 (first train) to 00:00 (last train) every day (including national holidays). The train frequency varies during the day, with a frequency of one train per 4-8 min.

\section{Field Study Design and Data Collection}

The measurement campaign entailed conducting investigations inside the train carriages of seven arranged routes in the Taipei MRT system during daytime (07:0017:00) from June 20 to August 8, 2016. During each monitoring session inside the train carriages, data were collected from the first station to the last station and then back to the first station. For example, on BR, the sampling was conducted from Taipei Zoo Station (BR01) to Nangang Exhibition Center Station (BR24) and then transferring to another train at Nangang Exhibition Center Station (BR24) back to Taipei Zoo Station (BR01). In this study, the sampling processes were conducted in five to six round trips on each route. Except for BR, sampling was always performed on the third or fourth car of the train and near the car's door to maintain a uniform sampling condition. For BR, sampling was conducted on the second or third car of the train.

In this study, a Grimm Series 1.108 Aerosol Spectrometer (Grimm Technologies, Inc., Douglasville, GA, USA) was used to measure the $\mathrm{PM}_{10}$ and $\mathrm{PM}_{2.5}$ levels and particle 


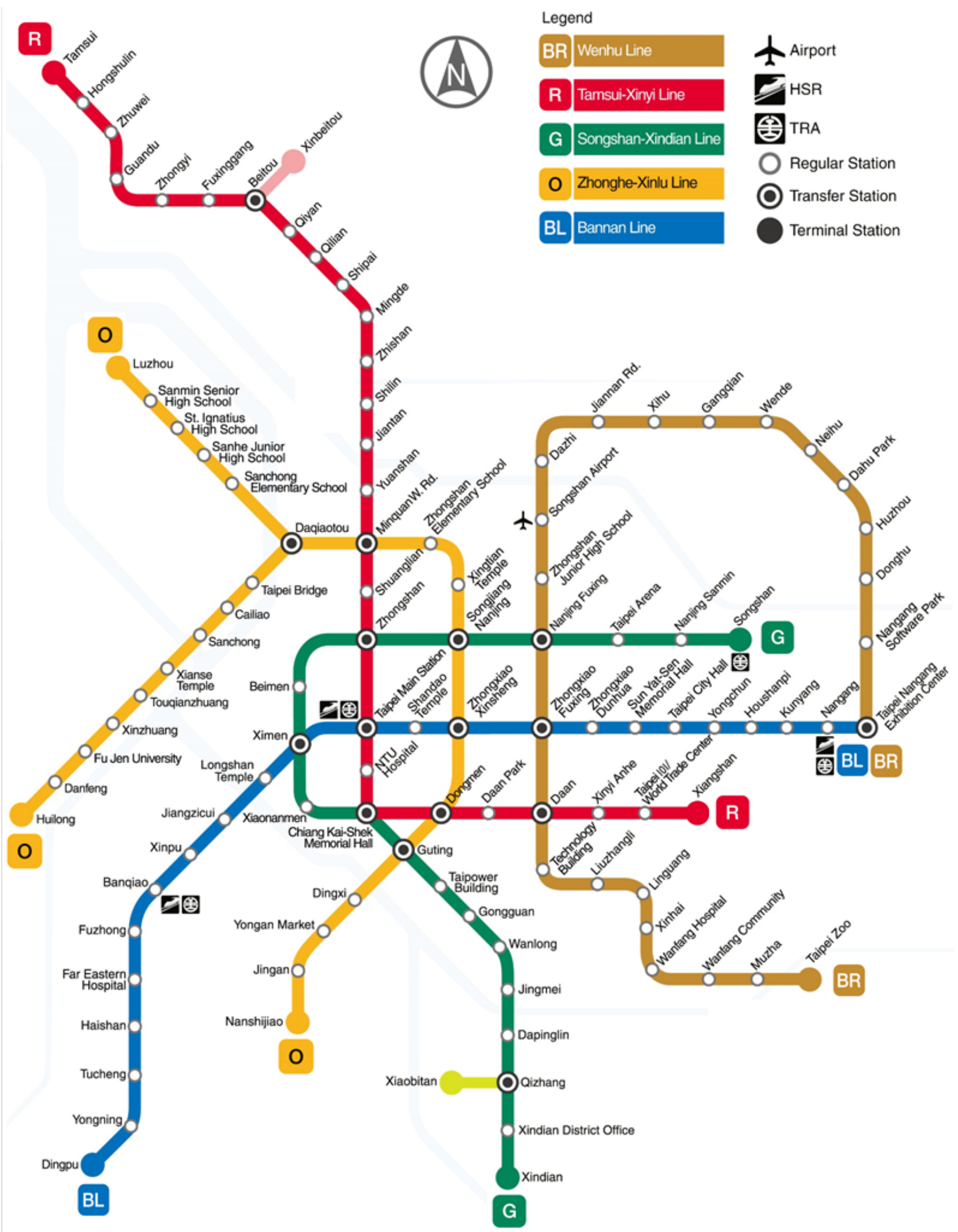

Copyright $\odot$ Taipei Rapid Transit Corporation

Fig. 1. Map of Taipei MRT system (Taipei Rapid Transit Corporation). 
(a)

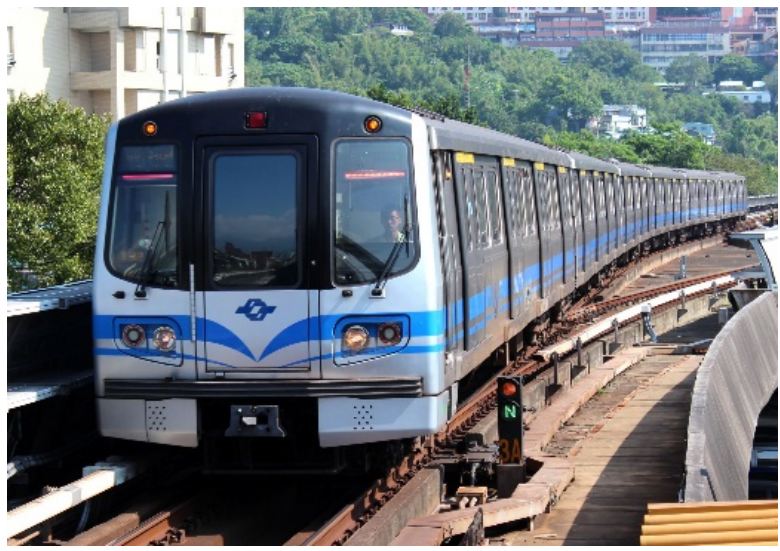

(c)

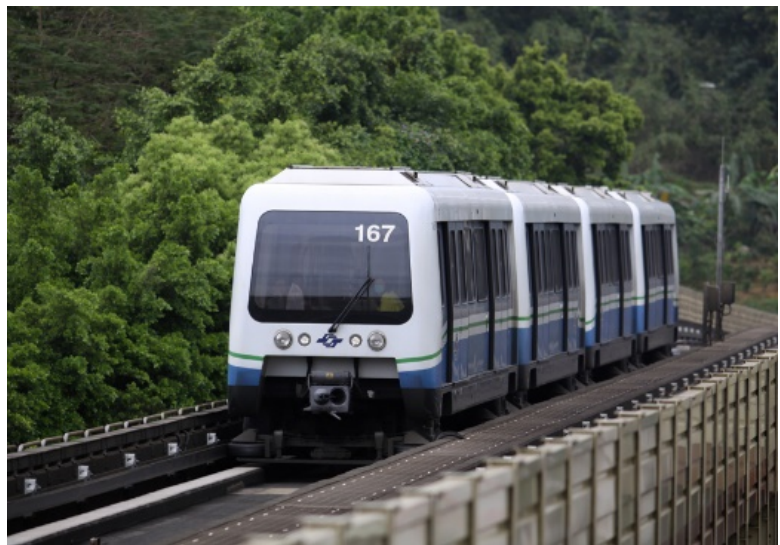

(b)

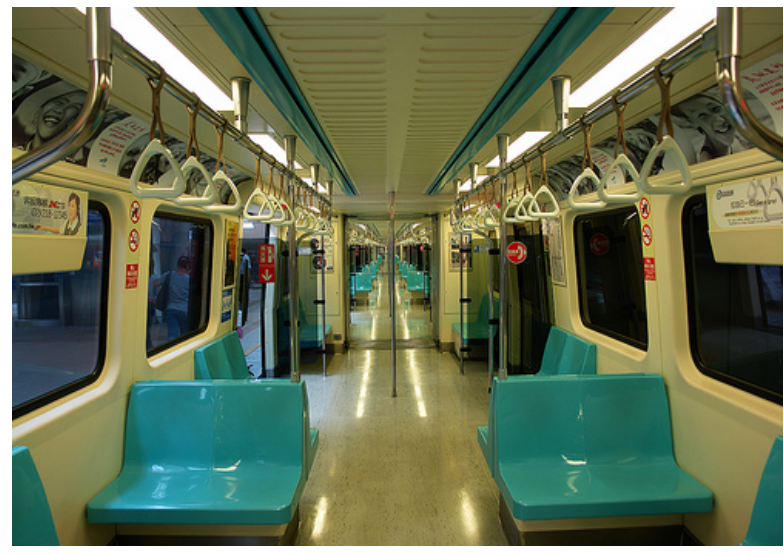

(d)

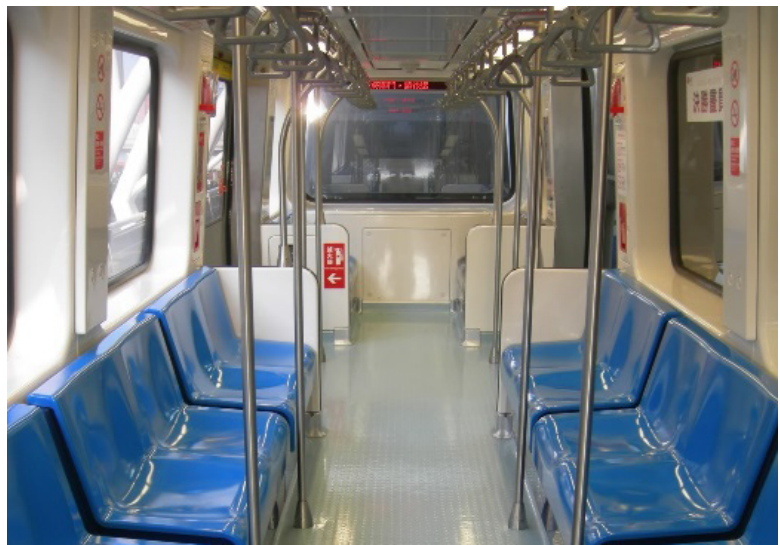

Fig. 2. Metro train cars used in the Taipei MRT system: (a) heavy-capacity train car exterior, (b) heavy-capacity train car interior, (c) medium-capacity train car exterior, and (d) medium-capacity train car interior.

Table 1. Features of selected routes.

\begin{tabular}{|c|c|c|c|c|}
\hline Route & & $\begin{array}{l}\text { Traveling Time } \\
\text { (min) }\end{array}$ & Length $(\mathrm{km})$ & $\begin{array}{l}\text { Number of } \\
\text { stations }\end{array}$ \\
\hline \multicolumn{5}{|c|}{ Ground-level } \\
\hline $\mathrm{BR}$ & Taipei Zoo (BR1)-Nangang Exhibition Center (BR24) & 45 & 25.7 & 24 \\
\hline $\mathrm{R}(\mathrm{G})$ & Yuanshan (R14)-Tamsui (R28) & 32 & 19.5 & 15 \\
\hline \multicolumn{5}{|c|}{ Underground } \\
\hline R (UG) & Xiangshan (R2)-Minquan W.Rd (R13) & 21 & 10.1 & 12 \\
\hline $\mathrm{G}$ & Xindian (G1)-Songshan (G19) & 36 & 19.4 & 19 \\
\hline $\mathrm{O}(\mathrm{A})$ & Nanshijiao (O1)-Huilong (O21) & 47 & 25.1 & 21 \\
\hline $\mathrm{O}(\mathrm{B})$ & Nanshijiao (O1)-Luzhou (O54) & 37 & 23.4 & 17 \\
\hline $\mathrm{BL}$ & Dingpu (BL1)-Nangang Exhibition Center (BL23) & 47 & 28.2 & 23 \\
\hline
\end{tabular}

mass size distributions. The advantages of this instrument are that it is lightweight, easy to operate, and good for time resolution. Moreover, this instrument also can provide good temporal resolution of particle mass size distribution. However, the response of the Grimm Aerosol Spectrometer may depend on the refractive index, and the shape, density and size of particles in different environments (Cheng, 2008; Cheng et al., 2011; Sousan et al., 2016). In previous studies, Cheng and Yan (2011) showed that PM levels measured by the Grimm Aerosol Spectrometer at outdoor environment did not significantly differ with those recorded by the ambient monitoring station in Taipei City. Additionally, Cheng (2008) demonstrated that PM levels measured by the Grimm Aerosol Spectrometer were approximately 0.75 times those evaluated by a reference gravimetric method in an iron foundry. Considering that the refractive index, the shape, and density of the PMs in the tunnel environment are unlike that of the PMs in urban environment. In addition, the PMs in the underground tunnel contains a high percentage of metallic iron (Querol et al., 2012; Cusack et al., 2015; Moreno et al., 2015). Therefore, data recorded by the Grimm Aerosol Spectrometer were postcalibrated with a factor of 1.3 and 1.0 inside train carriages on underground and ground-level routes, respectively, in this study. The measured size distributions were loaded into DistFit software (Chimera Tech., Inc., Forest Lake, MN, 
USA) to evaluate the $d p_{g}$ and $\sigma_{g}$ of the log-normal distribution function. A TSI Model 3007 Condensation Particle Counter (TSI Inc., Shoreview, MN, USA) was used to measure the PN concentration. Additionally, a TSI Model 7565 Q-Trak (TSI Inc., Shoreview, MN, USA) with an IAQ Probe 982 was used to measure the cabin air quality parameters, including $\mathrm{CO}_{2}$ level, temperature, and relative humidity. In this study, the nondispersive infrared sensor of $\mathrm{CO}_{2}$ was calibrated using zero gas and 3000 ppm $\mathrm{CO}_{2}$ standard gas before each sampling to avoid the measurements of drifted $\mathrm{CO}_{2}$ levels. All air samples were collected at approximately $1.5 \mathrm{~m}$ above the cabin floor, and the data logging interval for all measurements was set at $1 \mathrm{~min}$. Each $\mathrm{PM}_{10}, \mathrm{PM}_{2.5}$, and $\mathrm{PN}$ concentration inside the metro train carriage was estimated from one-way route average data. The mean, standard deviation, minimum, and maximum values for temperature, relative humidity, $\mathrm{CO}_{2}, \mathrm{PM}_{10}, \mathrm{PM}_{2.5}$, and $\mathrm{PN}$ are summarized in Table S1. An independentsamples $t$-test was conducted to evaluate differences in pollutant levels between the routes; a significance level of 0.05 was used for all statistical tests. The results of all independent-samples $t$-tests are summarized in Table S2.

Ambient hourly $\mathrm{PM}_{10}$ and $\mathrm{PM}_{2.5}$ concentrations were obtained from the Taiwan Air Quality Monitoring Network (TAQMN) at thirteen monitoring stations distributed in the Taipei metropolitan area. Over the same period, average $\mathrm{PM}_{10}$ and $\mathrm{PM}_{2.5}$ concentrations from these thirteen monitoring stations were considered as the corresponding outdoor $\mathrm{PM}_{10}$ and $\mathrm{PM}_{2.5}$ levels in the urban atmospheric environment in Taipei. Throughout the sampling period, the outdoor $\mathrm{PM}_{10}$ and $\mathrm{PM}_{2.5}$ concentrations were 20.6-59.8 $\mu \mathrm{g} \mathrm{m}^{-3}$ (mean = $38.3 \mu \mathrm{g} \mathrm{m}^{-3}$ ) and 7.1-37.2 $\mu \mathrm{g} \mathrm{m}^{-3}\left(\right.$ mean $\left.=18.4 \mu \mathrm{g} \mathrm{m}^{-3}\right)$, respectively. Furthermore, the outdoor temperature was $28.7-37.3^{\circ} \mathrm{C}\left(\right.$ mean $\left.=32.4^{\circ} \mathrm{C}\right)$ and relative humidity was $39.5-89.4 \%($ mean $=64.6 \%)$.

\section{RESULTS AND DISCUSSION}

\section{Temperature, Relative Humidity, and $\mathrm{CO}_{2}$ inside Metro Train Carriages}

Fig. 3 shows the temperature, relative humidity, and $\mathrm{CO}_{2}$ levels inside the metro train carriages of the seven selected routes. During the entire sampling period, the temperature inside the metro train carriages was $22.8^{-}$ $29.9^{\circ} \mathrm{C}\left(\right.$ mean $\left.=25.6^{\circ} \mathrm{C}\right)$ and relative humidity was 46.9 $77.8 \%$ (mean $=66.8 \%)$. The temperature inside the metro train carriages was not significantly different among these metro lines (all $\mathrm{p} \geq 0.075$ ); by contrast, the relative humidity was slightly different. The relative humidity inside the metro train carriages on $\mathrm{G}, \mathrm{O}(\mathrm{A}), \mathrm{O}(\mathrm{B})$, and $\mathrm{BL}$ was significantly higher than that inside carriages on $\mathrm{BR}$ and $\mathrm{R}(\mathrm{G})$ (all $\mathrm{p} \leq 0.008)$. Additionally, the relative humidity was not significantly different among $\mathrm{G}, \mathrm{O}(\mathrm{A}), \mathrm{O}(\mathrm{B})$, and $\mathrm{BL}$ (all $\mathrm{p} \geq 0.096$ ). For $\mathrm{R}$, the relative humidity was not significantly different between $\mathrm{R}(\mathrm{G})$ and $\mathrm{R}(\mathrm{UG})(\mathrm{p}=$ 0.520 ), but the relative humidity on $\mathrm{R}$ (UG) was still approximately $3 \%$ higher than that on $R(G)$. According to the measurement results, the variations in relative humidity on ground-level routes were more easily affected by ambient conditions, as compared with those on underground routes.

During the entire sampling period, the $\mathrm{CO}_{2}$ levels inside metro train carriages were 668-1751 ppm (mean = 1019 ppm). The mean $\mathrm{CO}_{2}$ level inside the metro train carriages was approximately 2 times higher than that in the outdoor environment and is close to the Taiwan EPA Indoor Air Quality Standard (1000 ppm for $8 \mathrm{~h}$ ). No evidence exists that the $\mathrm{CO}_{2}$ level inside metro train carriages on the underground routes is certainly higher than that on the ground-level routes. According to the measurement results, the highest mean $\mathrm{CO}_{2}$ concentration was observed on R (UG), followed by R (G), BL, and O (B). Nevertheless, the $\mathrm{CO}_{2}$ levels among these four routes were not significantly different (all $\mathrm{p} \geq 0.277$ ). The variations in $\mathrm{CO}_{2}$ inside the metro train carriages had the same trend for all routes. Overall, $\mathrm{CO}_{2}$ buildup could be observed when the train reached the downtown area because of an increased number of commuters; however, the $\mathrm{CO}_{2}$ level dropped rapidly as the number of commuters decreased when the train was outbound. Recently, a similar result had been obtained by $\mathrm{Xu}$ et al. (2016). Additionally, the $\mathrm{CO}_{2}$ level reached over $1000 \mathrm{ppm}$ in the downtown area, which is higher than the Taiwan EPA Indoor Air Quality Standard. Previous studies have demonstrated that the $\mathrm{CO}_{2}$ level inside metro train carriages was proportional to the ridership (Park and Ha, 2008; Kam et al., 2011; Cheng et al., 2012; Martins et al., 2015). Clearly, the $\mathrm{CO}_{2}$ level inside metro train carriages was elevated by the exhalation of commuters and could have accumulated when air was recirculating without sufficient fresh air.

\section{$\mathrm{PM}_{10}$ and $\mathrm{PM}_{2.5}$ Concentrations inside Metro Train Carriages}

Fig. 4 shows the $\mathrm{PM}_{10}$ and $\mathrm{PM}_{2.5}$ concentrations inside the metro train carriages on the seven selected routes. The measurement results showed that $\mathrm{PM}_{10}$ levels inside the metro train carriages were in the range of 2.9-134.5 $\mu \mathrm{g} \mathrm{m}^{-3}$ (mean $=54.7 \mu \mathrm{g} \mathrm{m}^{-3}$ ) during the entire sampling period. The highest mean $\mathrm{PM}_{10}$ level was observed on $\mathrm{O}(\mathrm{B})$, followed by $\mathrm{O}(\mathrm{A}), \mathrm{G}, \mathrm{BL}, \mathrm{R}(\mathrm{UG}), \mathrm{BR}$, and R (G). On the underground routes, the $\mathrm{PM}_{10}$ levels between $\mathrm{O}(\mathrm{B})$ and $\mathrm{O}(\mathrm{A})(\mathrm{p}=0.245)$ were not significantly different. However, the $\mathrm{PM}_{10}$ level on $\mathrm{O}(\mathrm{B})$ was significantly higher than those on $\mathrm{G}, \mathrm{BL}$, and $\mathrm{R}(\mathrm{UG})$ (all $\mathrm{p} \leq 0.015$ ). Furthermore, the $\mathrm{PM}_{10}$ levels between $\mathrm{O}(\mathrm{A})$ and $\mathrm{G}(\mathrm{p}=0.188)$ were not significantly different. However, the $\mathrm{PM}_{10}$ level on $\mathrm{O}(\mathrm{A})$ was significantly higher than those on BL and R (UG) (all $\mathrm{p} \leq 0.001)$. The $\mathrm{PM}_{10}$ levels between $\mathrm{BL}$ and $\mathrm{R}(\mathrm{UG})(\mathrm{p}=$ $0.796)$ were not significantly different. Nevertheless, the $\mathrm{PM}_{10}$ level on $\mathrm{R}(\mathrm{UG})$ was significantly lower than those on $\mathrm{O}(\mathrm{B}), \mathrm{O}(\mathrm{A})$, and $\mathrm{G}$ (all $\mathrm{p} \leq 0.006$ ). On the groundlevel routes, the PM10 levels were not significantly different between $B R$ and $R(G)(p=0.075)$. Clearly, $P_{10}$ levels inside metro train carriages on the underground routes were significantly higher than (all $\mathrm{p}<0.001$ ) and approximately 3.4-9.3 times those on the ground-level routes.

The measurement results also revealed that the $\mathrm{PM}_{2.5}$ levels inside the metro train carriages were in the range of 


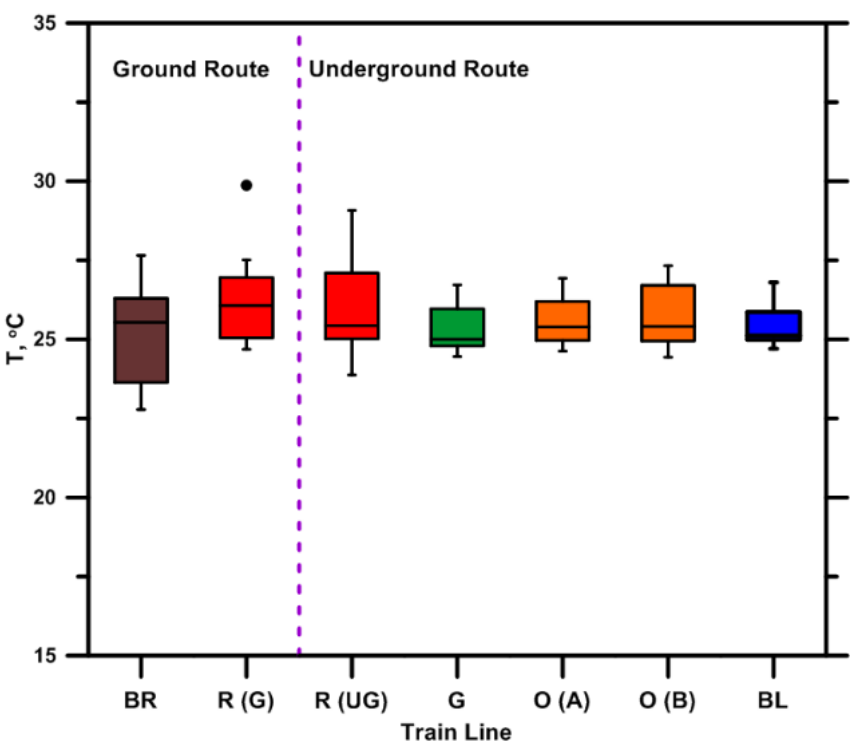

(a)

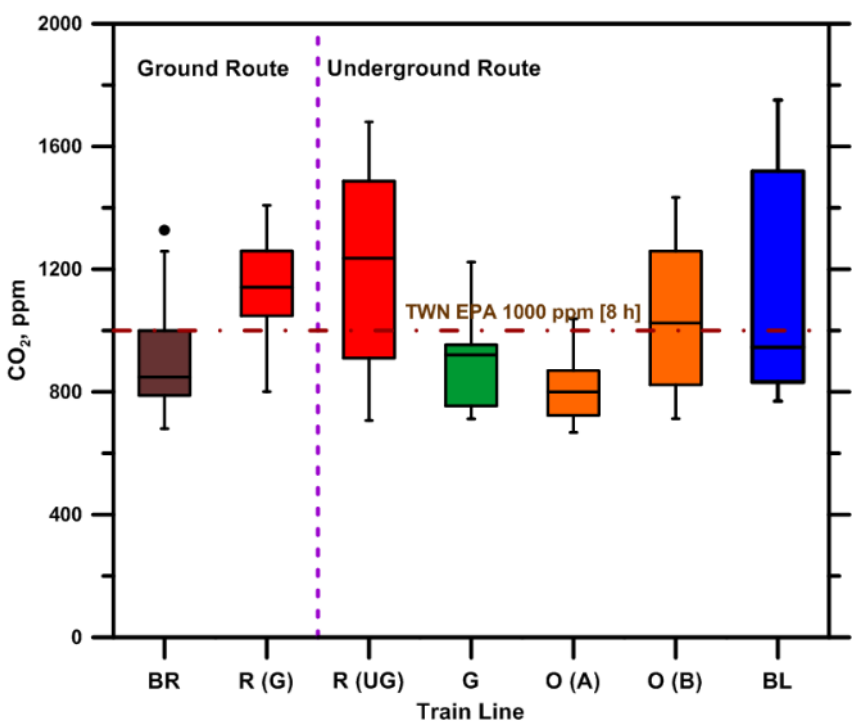

(c)

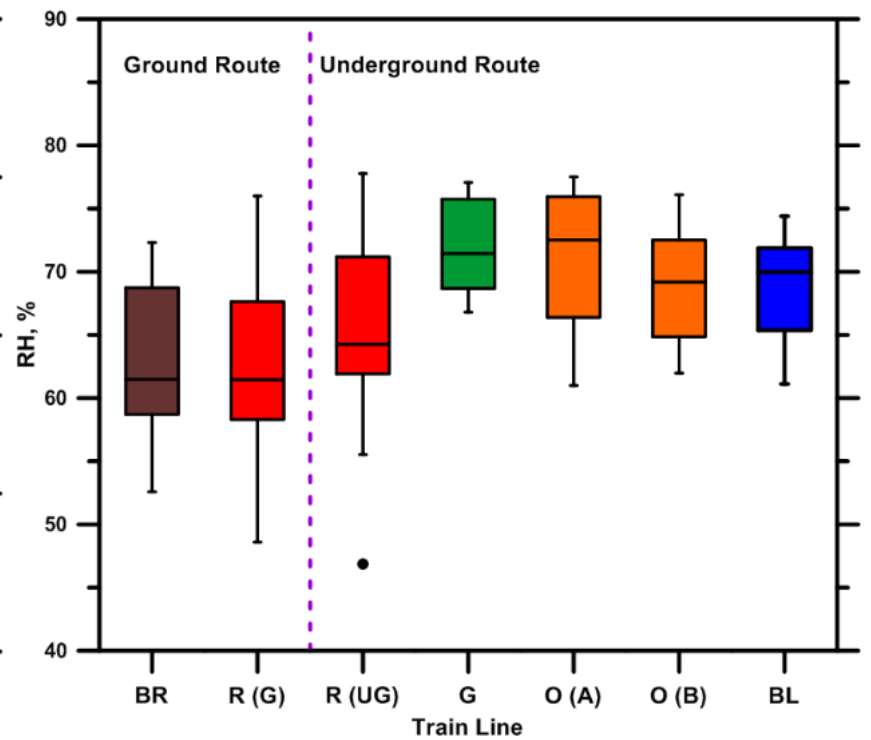

(b)

Fig. 3. (a) Temperature, (b) relative humidity, and (c) $\mathrm{CO}_{2}$ levels inside metro train carriages on seven selected routes.

1.5-112.4 $\mu \mathrm{g} \mathrm{m}^{-3}$ (mean $=47.4 \mu \mathrm{g} \mathrm{m}^{-3}$ ) during the entire sampling period. The level distribution of $\mathrm{PM}_{2.5}$ was similar to that of $\mathrm{PM}_{10}$. The highest mean $\mathrm{PM}_{2.5}$ level was observed on $\mathrm{O}(\mathrm{B})$, followed by $\mathrm{O}(\mathrm{A}), \mathrm{G}, \mathrm{BL}, \mathrm{R}$ (UG), $\mathrm{BR}$, and $\mathrm{R}(\mathrm{G})$. On the underground routes, the $\mathrm{PM}_{2.5}$ levels between $\mathrm{O}(\mathrm{B})$ and $\mathrm{O}(\mathrm{A})(\mathrm{p}=0.274)$ were not significantly different. However, the $\mathrm{PM}_{2.5}$ level on $\mathrm{O}(\mathrm{B})$ was significantly higher than those on $\mathrm{G}, \mathrm{BL}$, and R (UG) (all $\mathrm{p}$ $\leq 0.022$ ). In addition, the $\mathrm{PM}_{2.5}$ levels between $\mathrm{O}(\mathrm{A})$ and $\mathrm{G}(\mathrm{p}=0.220)$ were not significantly different. Nevertheless, the $\mathrm{PM}_{2.5}$ level on $\mathrm{O}(\mathrm{A})$ was significantly higher than those on BL and R (UG) (all $\mathrm{p} \leq 0.001$ ). The $\mathrm{PM}_{2.5}$ levels between $B L$ and $R(U G)(p=0.445)$ were not significantly different. However, the $\mathrm{PM}_{2.5}$ level on $\mathrm{R}$ (UG) was significantly lower than those on $\mathrm{O}(\mathrm{B}), \mathrm{O}(\mathrm{A})$, and $\mathrm{G}$ (all $\mathrm{p} \leq 0.003)$. Unlike the $\mathrm{PM}_{10}$ level on the ground-level routes, the $\mathrm{PM}_{2.5}$ level on $\mathrm{BR}$ was significantly higher than that on $R(G)(p=0.010)$. Clearly, the $P_{2.5}$ levels inside metro train carriages on the underground routes were significantly higher than (all $\mathrm{p}<0.001$ ) those on the groundlevel routes by approximately 3.1-10.2 times. Additionally, the $\mathrm{PM}_{2.5}$ level on the underground routes reached over $35 \mu \mathrm{g} \mathrm{m}^{-3}$, which is higher than the Taiwan EPA Indoor Air Quality Standard.

Despite the different metro routes, these findings suggest that the $\mathrm{PM}_{10}$ and $\mathrm{PM}_{2.5}$ levels inside metro train carriages were remarkably affected by the surrounding conditions of the trains, such as their journey in underground tunnels or on ground-level tracks. Kam et al. (2011) and Cheng et al. (2012) have also demonstrated the same results, revealing that $\mathrm{PM}_{10}$ and $\mathrm{PM}_{2.5}$ levels inside metro train carriages in underground environments were higher than those in above-ground environments, even for those measured on different metro lines. 


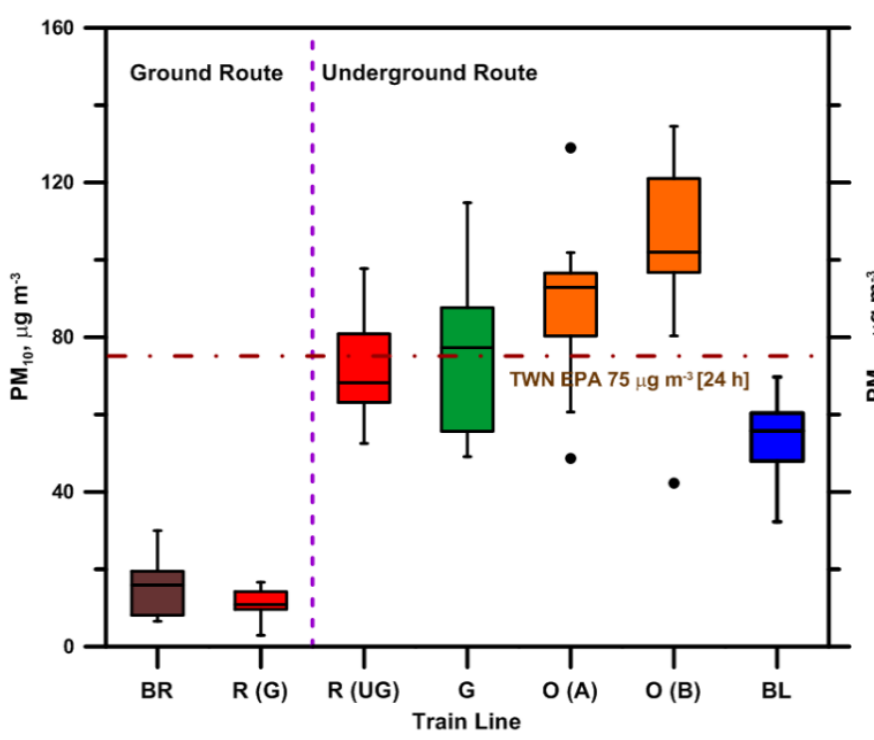

(a)

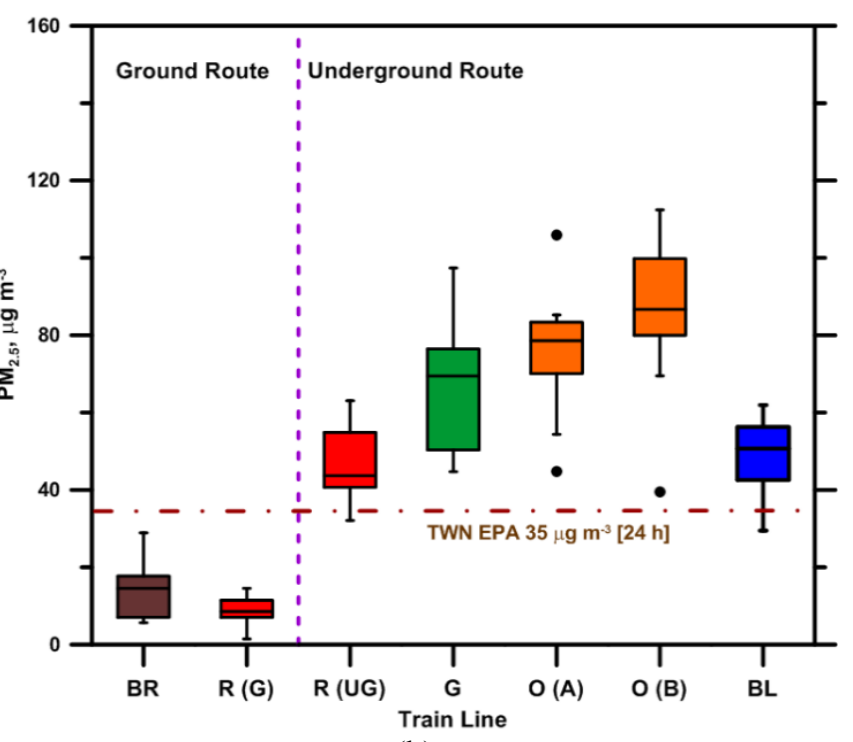

(b)

Fig. 4. (a) $\mathrm{PM}_{10}$ and (b) $\mathrm{PM}_{2.5}$ concentrations inside metro train carriages on seven selected routes.

\section{Effect of Outdoor Ambient Air Conditions on PM Levels inside Metro Train Carriages}

Fig. 5 shows the relationships between indoor and outdoor $\mathrm{PM}_{10}$ and $\mathrm{PM}_{2.5}$ concentrations on the ground-level and underground routes. According to the measurement results, the $\mathrm{PM}_{10}$ and $\mathrm{PM}_{2.5}$ concentrations inside metro train carriages on the ground-level routes exhibited a remarkable positive correlation with the outdoor $\mathrm{PM}_{10}$ and $\mathrm{PM}_{2.5}$ concentrations, and they were approximately only 0.3 and 0.6 times the outdoor ambient $\mathrm{PM}_{10}$ and $\mathrm{PM}_{2.5}$ concentrations, respectively, on average. However, the outdoor and indoor $\mathrm{PM}_{10}$ and $\mathrm{PM}_{2.5}$ concentrations were less correlated on the underground routes, and the $\mathrm{PM}_{10}$ and $\mathrm{PM}_{2.5}$ concentrations inside metro train carriages on the underground routes were approximately 2.1 and 4.2 times the outdoor ambient $\mathrm{PM}_{10}$ and $\mathrm{PM}_{2.5}$ concentrations, respectively, on average. Clearly, the $\mathrm{PM}_{10}$ and $\mathrm{PM}_{2.5}$ concentrations inside metro train carriages on the groundlevel routes were directly affected by the outdoor ambient air conditions. However, these concentrations on the underground routes were remarkably influenced by the underground tunnel conditions. The PM in the underground tunnels could have been generated from outdoor ambient air through the tunnel ventilation systems or internally generated by the train operations. The measurement results clearly demonstrate that the air quality inside the underground tunnels was worse than that of the outdoor ambient environment. PM can much more easily infiltrate metro train carriages when trains are traveling in isolated underground environments, due to the greater wind pressure in tunnel environments when compared with that in atmospheric environments. Therefore, the $\mathrm{PM}_{10}$ and $\mathrm{PM}_{2.5}$ levels inside metro train carriages on the underground routes could be aggravated when compared with those on ground-level routes. The measurement results also indicate that the filtration capacities of the metro train cars in the Taipei MRT system were not sufficient to remove PM effectively for trains traveling in underground environments.

\section{PN inside Metro Train Carriages}

Fig. 6 shows the PN concentrations inside metro train carriages on the seven selected routes. The measurement results showed that the $\mathrm{PN}$ levels inside train carriages were in the range of $6.6 \times 10^{3}$ to $2.8 \times 10^{4}$ particles $\mathrm{cm}^{-3}$ $\left(\right.$ mean $=1.3 \times 10^{4}$ particles $\mathrm{cm}^{-3}$ ) during the entire sampling period. The highest mean PN level was observed on BR, followed by R (G), O (B), O (A), BL, R (UG), and G. Unlike PM, the PN levels on the ground-level routes were significantly higher than those on the underground routes (all $\mathrm{p} \leq 0.003$ ). On the ground-level routes, the PN levels between BR and $\mathrm{R}(\mathrm{G})$ were not significantly different $(\mathrm{p}=$ 0.734). Moreover, the $P N$ levels were not significantly different between $\mathrm{O}(\mathrm{B})$ and $\mathrm{O}(\mathrm{A})(\mathrm{p}=0.736)$ or among $\mathrm{BL}, \mathrm{R}(\mathrm{UG})$, and $\mathrm{G}$ (all $\mathrm{p} \geq 0.056$ ) on the underground routes. The PN levels on $\mathrm{O}(\mathrm{B})$ and $\mathrm{O}(\mathrm{A})$ were significantly higher than those on BL, R (UG), and G (all $\mathrm{p} \leq 0.021$ ). Seaton et al. (2005) reported that PN levels inside train carriages in the London Underground were approximately $30-60 \%$ lower than those in outdoor environments. Cheng et al. (2012) demonstrated that PN levels inside train carriages on underground and ground-level routes were approximately $0.24-0.31$ and $0.33-0.37$ times those in outdoor ambient environments, respectively. These measurement results indicate that the PN levels inside train carriages were also significantly affected by traveling environmental conditions - in underground tunnels or on ground-level tracks. Moreover, compared with the PM levels, the measurement results reveal that PM generated inside tunnels was fine and coarse, which could remarkably elevate the particle mass concentrations but exert less influence on the PN concentrations. Therefore, no remarkable emission source of ultrafine particles exists in underground tunnels. The origin of ultrafine particles inside tunnels is related to outdoor air pollutants from vehicle traffic on 
(a)

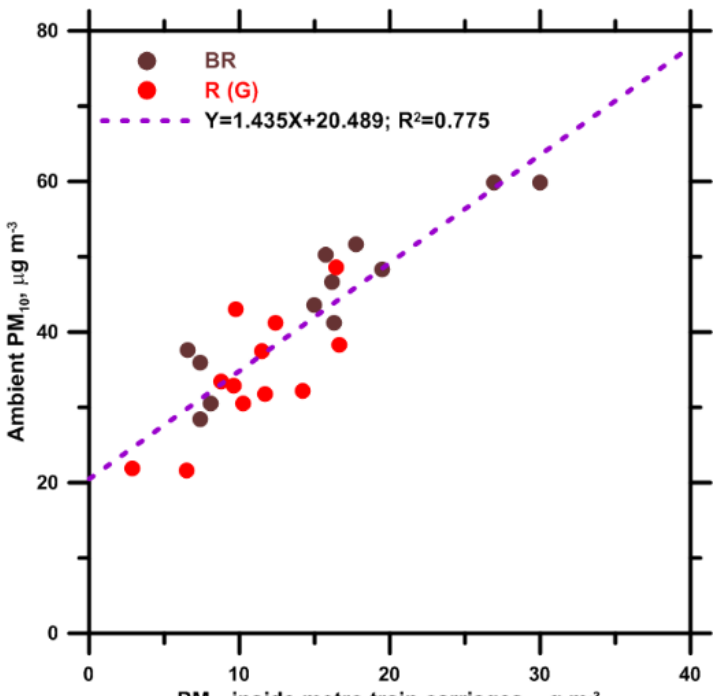

(c)

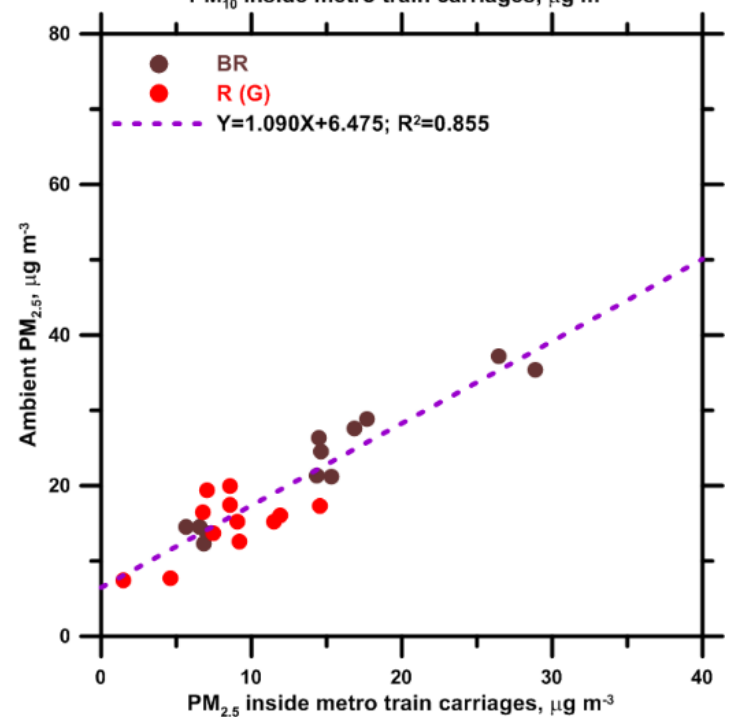

(b)

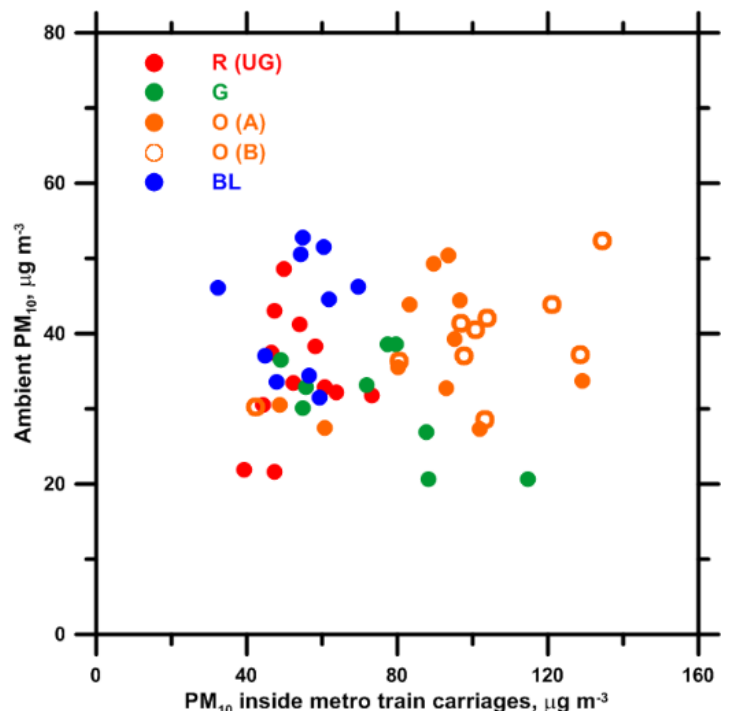

(d)

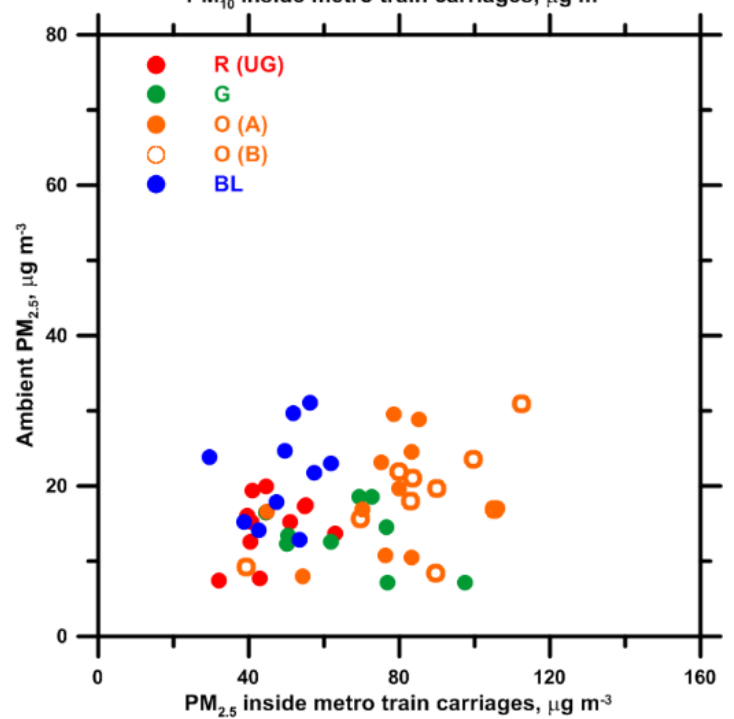

Fig. 5. Relationships between indoor and outdoor $\mathrm{PM}_{10}$ levels on (a) ground-level routes and (b) underground routes and between indoor and outdoor $\mathrm{PM}_{2.5}$ levels on (c) ground-level routes and (d) underground routes.

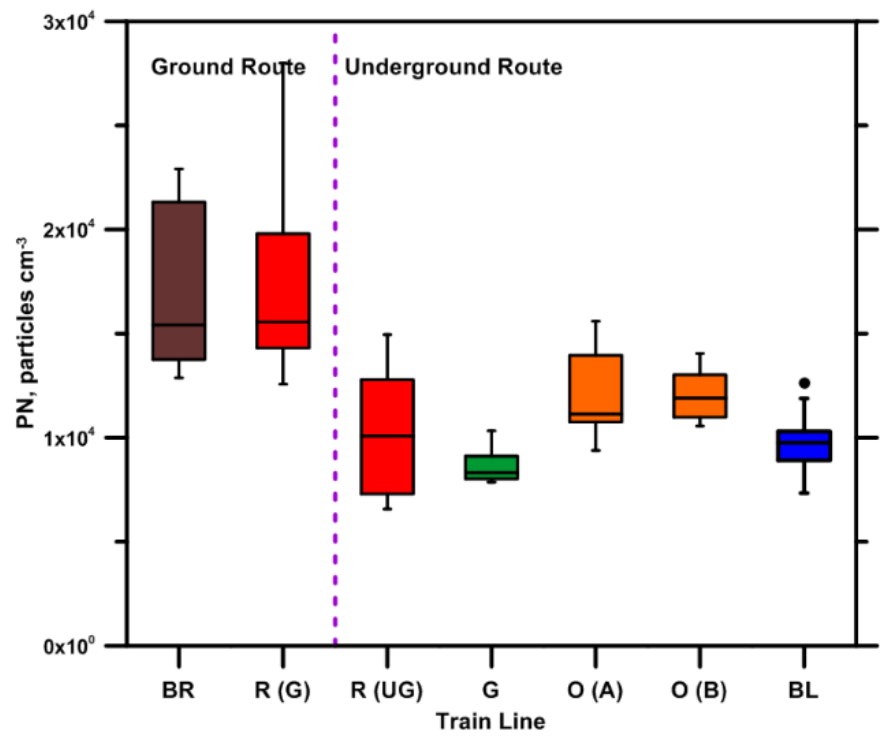

Fig. 6. PN concentrations inside metro train carriages on seven selected routes 
nearby streets, and these particles could be transported from outside through the tunnel ventilation systems.

\section{Particle Mass Size Distributions inside Metro Train Carriages}

Few previous studies have reported particle mass size distributions inside metro train carriages. Fig. 7 shows the particle mass size distributions inside metro train carriages in the Taipei MRT system. According to the measurement results, the log-normal particle mass size distributions inside metro train carriages exhibited a clear triple mode: an accumulation mode, a coarse mode, and a very coarse mode. However, the particle mass size distribution patterns between the ground-level and underground routes were considerably different. On the ground-level routes, the dominant mode was at approximately $0.3 \mu \mathrm{m}$, whereas the two minor modes were at 2.6 and $10.4 \mu \mathrm{m}$, respectively. On the ground-level routes, this accumulation mode was similar to those in the outdoor ambient environment, suggesting that the fine particles $\left(\mathrm{d}_{\mathrm{p}}<1.0 \mu \mathrm{m}\right)$ inside metro train carriages were directly transferred from outdoor ambient air and associated with the surrounding conditions of the trains. Cheng and Yan (2011) revealed that particle mass size distributions exhibited a double-mode pattern in the outdoor environment, with the accumulation and coarse modes being at 0.3 and $3.5 \mu \mathrm{m}$, respectively. Compared with the measurement results of Cheng and Yan (2011), the coarse particles $\left(\mathrm{d}_{\mathrm{p}} \approx 1.0-6.0 \mu \mathrm{m}\right)$ and very coarse particles $\left(\mathrm{d}_{\mathrm{p}}>6.0 \mu \mathrm{m}\right)$ inside metro train carriages on both the ground-level and underground routes were likely caused by train operations and indoor activities, respectively, and were less related to the outdoor ambient conditions. These coarse particles $\left(\mathrm{d}_{\mathrm{p}} \approx 1.0-6.0 \mu \mathrm{m}\right)$ were probably associated with train operations and transferred from outside of train cars. The particles generated through mechanical friction between wheel and rail, between wheel and brake pad, and between conductor rail and collector shoe could be in this size range (Jung et al., 2012; Şahin et al., 2012; Cusack et al., 2015). Additionally, the very coarse particles $\left(\mathrm{d}_{\mathrm{p}}>\right.$ $6.0 \mu \mathrm{m})$ inside metro train carriages could be attributed to particle resuspension engendered by the movement of commuters when boarding trains or alighting from them (Cheng et al., 2012). These resuspended particles from the cabin floor could have aggregated to form large particles. Nevertheless, these two modes, coarse and very coarse, were very minor when compared with the accumulation mode on BR. One possible reason is that coarse particles can be easily filtered out by the ventilation system of BR because the train cars on BR are smaller than those on other routes (Fig. 2). Another reason is that the coarse particles generated from mechanical friction on BR are fewer than those on other routes because the train cars of BR use rubber tires. Cartenì and Cascetta (2018) showed that the PM concentrations measured inside trains in a high-quality rubber-tired metro system were significantly lower than those measured in traditional railway systems.

On the underground routes, the primary and secondary dominant modes were at approximately 0.5 and $2.1 \mu \mathrm{m}$, respectively, and the minor mode was at approximately $9.1 \mu \mathrm{m}$. Clearly, the accumulation mode of the particle mass size distributions on the underground routes was larger than that on the ground-level routes. These fine particles $\left(d_{p}<1.0 \mu \mathrm{m}\right)$ might have originated from the outdoor environment and increased in size through particle coagulation inside underground tunnels. Additionally, a remarkable coarse mode could be observed on the underground routes when compared with the ground-level routes. As mentioned, these coarse $\left(\mathrm{d}_{\mathrm{p}} \approx 1.0-6.0 \mu \mathrm{m}\right)$ particles were probably associated with train operations, and they accounted for approximately $18-30 \%$ of the total particle mass on the underground routes. Unlike the ground-level routes, these coarse particles generated by train operations in underground tunnels were not easily dispersed.

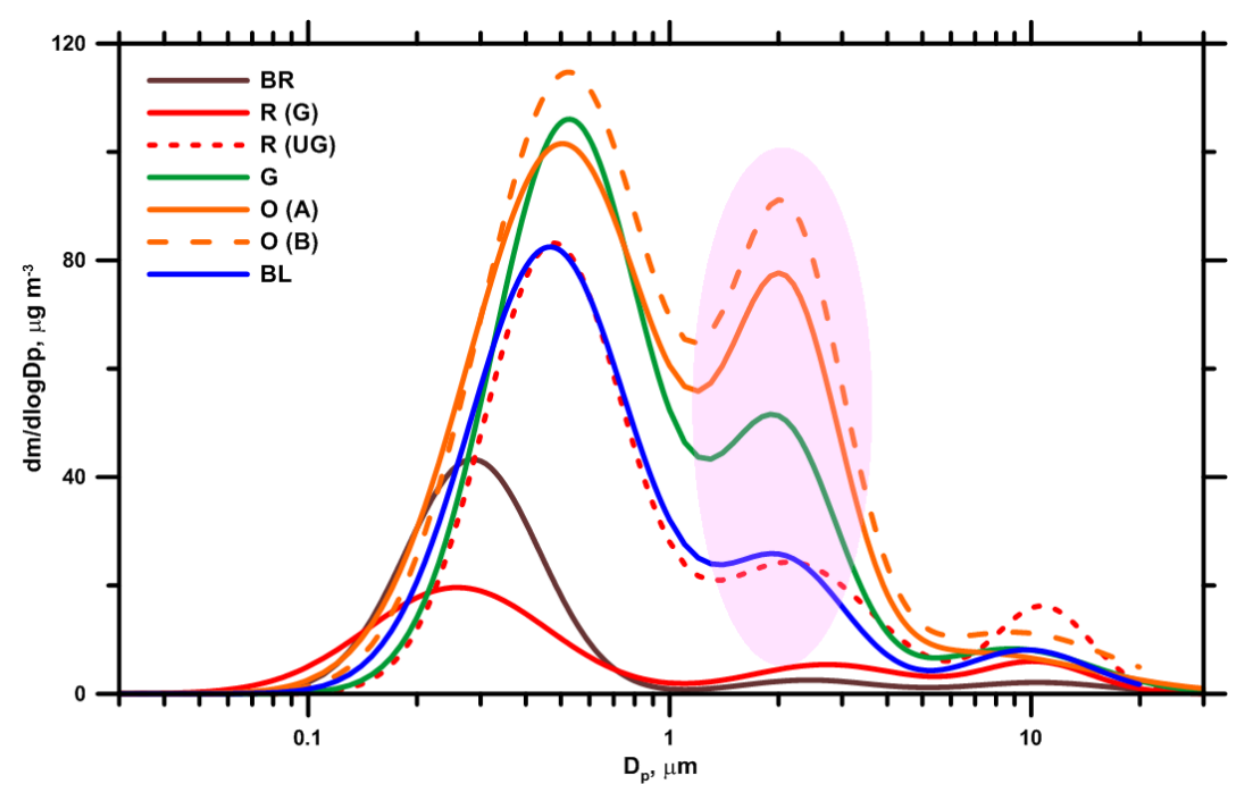

Fig. 7. Particle mass size distributions inside metro train carriages on seven selected routes. 


\section{Real-time Variations in $P M_{10}, P M_{2.5}$, and $P N$ Concentrations and Particle Mass Size Distributions inside Metro Train Carriages}

Fig. 8 shows the variation trends of $\mathrm{PM}_{10}, \mathrm{PM}_{2.5}$, and $\mathrm{PN}$ concentrations and particle mass size distributions inside metro train carriages on BR for both travel directions. The curves were obtained for averaged data of five to six oneway trips. Except for the route between Airport Station (BR13) and Dazhi Station (BR14), the trains ran on ground level. The $\mathrm{PM}_{10}$ and $\mathrm{PM}_{2.5}$ levels inside metro train carriages on BR were relatively stable throughout the travel time when compared with other routes. In addition, the particle mass size distributions did not change remarkably. However, the PN levels varied significantly due to the change in outdoor ambient conditions. An increase in the PN level could be observed when the train reached the city center area because of the presence of a larger traffic volume when compared with that outside the city center; by contrast, the PN level decreased when the train was outbound. Clearly, the PN levels inside metro train carriages decreased when the train ran in the underground section. When the train ran out from the underground section, the PN levels inside metro train carriages increased. Nevertheless, the difference in the variation trend of PN levels was remarkably affected by the train travel direction. In the underground section, the PN levels decreased slightly at the direction from suburb to city center and decreased significantly at the opposite direction from city center to suburb. This difference depended on the outdoor ambient PN levels before train running into the underground section. Therefore, the PN levels inside metro train carriages were more sensitive to the outdoor ambient conditions when compared with the $\mathrm{PM}_{10}$ and $\mathrm{PM}_{2.5}$ levels on the ground-level routes. Moreover, measurement results also showed that the $\mathrm{PM}_{10}$ and $\mathrm{PM}_{2.5}$ levels inside metro train carriages could be elevated when the train ran in the underground section, but the elevated levels were not obvious compared with $\mathrm{R}$ Line. A possible reason is that the length of the underground section could influence this result. In this study, the underground section of BR is only approximately $3.1 \mathrm{~km}$ and the $\mathrm{R}$ is roughly $10.1 \mathrm{~km}$.

Fig. 9 shows the variation trends of $\mathrm{PM}_{10}, \mathrm{PM}_{2.5}$, and $\mathrm{PN}$ concentrations and particle mass size distributions inside metro train carriages on $\mathrm{R}$ for both travel directions. $\mathrm{R}$ is the only route among these heavy-capacity metro lines in the Taipei MRT system that has both underground and ground-level sections. According to the measurement results, the $\mathrm{PM}_{10}$ and $\mathrm{PM}_{2.5}$ levels decreased and the $\mathrm{PN}$

(a)

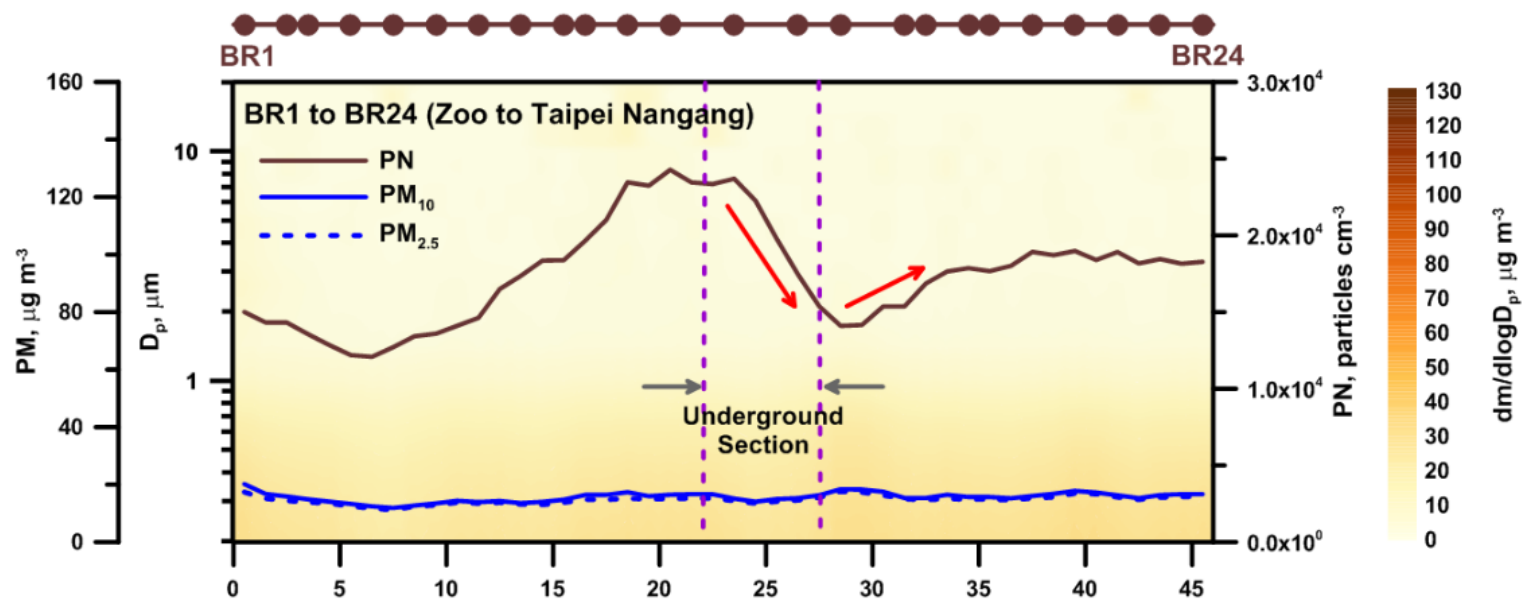

(b)

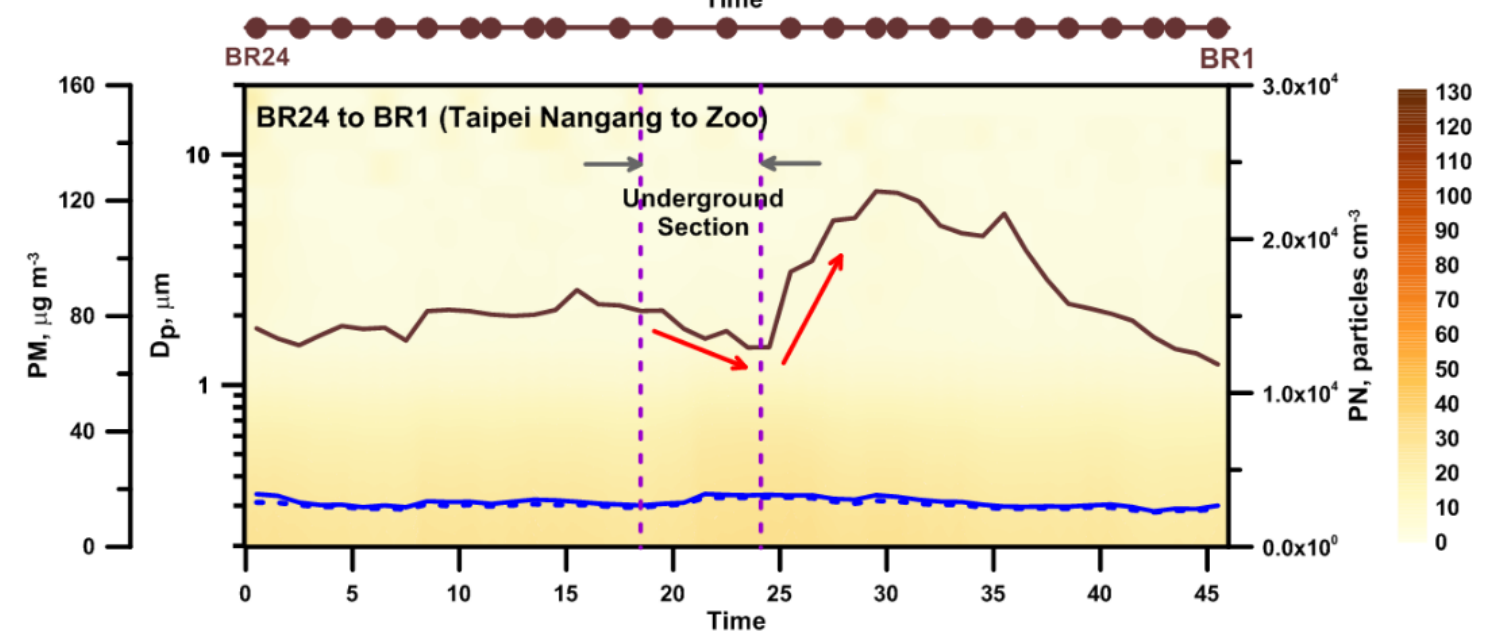

Fig. 8. Variation trends of $\mathrm{PM}_{10}, \mathrm{PM}_{2.5}$, and $\mathrm{PN}$ concentrations and particle mass size distributions inside metro train carriages on BR from (a) BR01 to BR24 and (b) BR24 to BR01. 
(a)

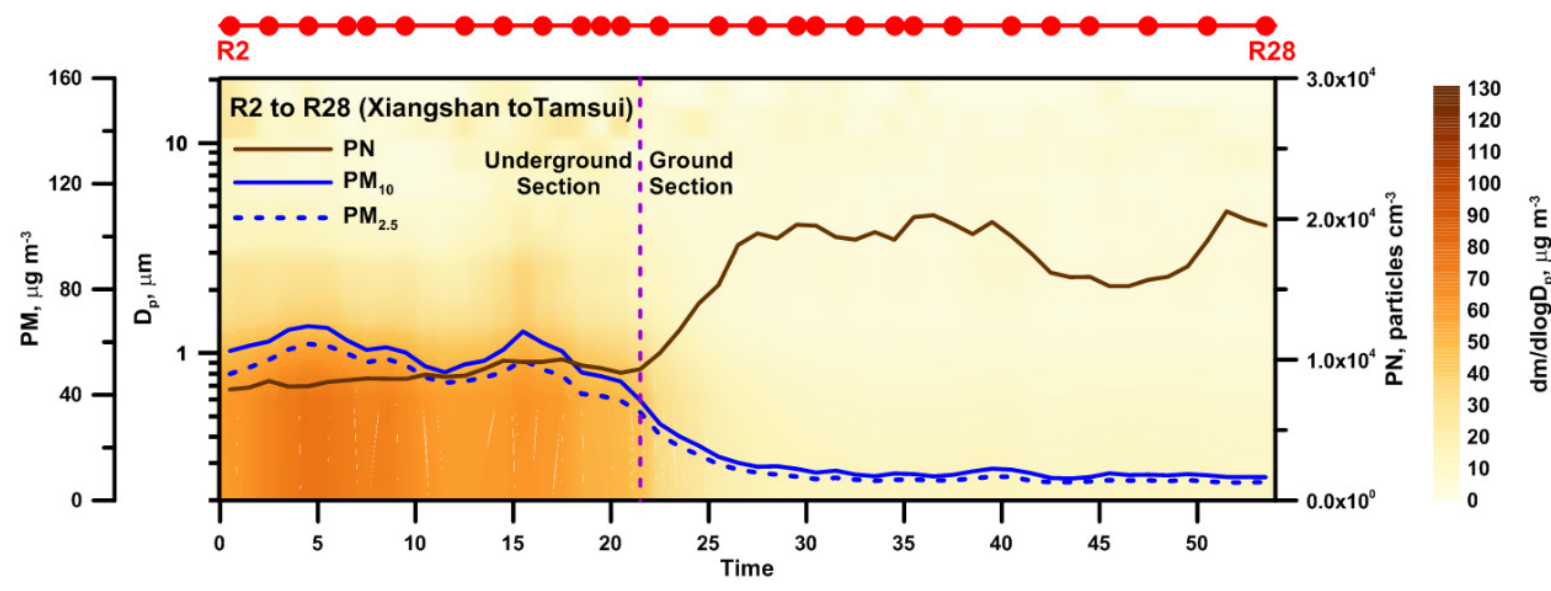

(b)

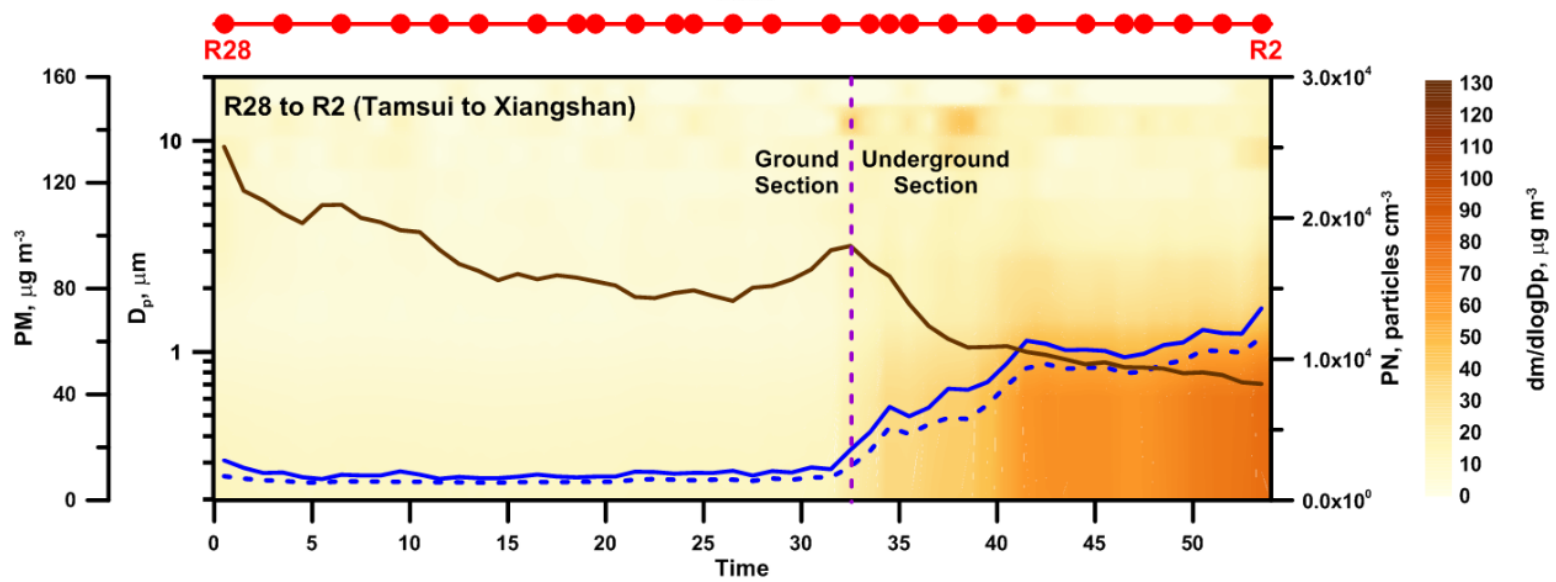

Fig. 9. Variation trends of $\mathrm{PM}_{10}, \mathrm{PM}_{2.5}$, and $\mathrm{PN}$ concentrations and particle mass size distributions inside metro train carriages on R from (a) R02 to R28 and (b) R28 to R02.

level increased after the train ran out of the underground section. In the opposite travel direction, an inverted trend was observed for the $\mathrm{PM}_{10}, \mathrm{PM}_{2.5}$, and $\mathrm{PN}$ levels after the train ran into the underground section. The highest PN level could be observed at Tamsui Station (R28) when the train departed from this station to Xiangshan Station (R02). A possible reason is that the ultrafine particles outside the train transferred into the train carriages when the train stopped on the platform and the train doors were opened for commuters, who boarded the train with an interval of approximately 2-4 min before the train departed. Clearly, the $\mathrm{PM}_{10}$ and $\mathrm{PM}_{2.5}$ levels observed inside the metro train carriages were higher in the underground section than in the ground-level section. Moreover, the PN level observed inside the metro train carriages was lower in the underground section than in the ground-level section. The variations in particle mass size distributions were also affected by the travel environments (in underground tunnels or on ground-level tracks) and directions. Cartenì et al. (2015) reported similar trends of $\mathrm{PM}_{10}$ and $\mathrm{PM}_{2.5}$ levels inside metro train carriages when trains were traveling between ground-level and underground sections.

Fig. 10 shows the variation trends of $\mathrm{PM}_{10}, \mathrm{PM}_{2.5}$, and PN concentrations and particle mass size distributions inside the metro train carriages on $\mathrm{O}$ for both travel directions. O currently runs on two separate routes: $\mathrm{O}$ (A) and $\mathrm{O}(\mathrm{B})$. On these routes, the train runs on the same section between Nanshijiao Station (O01) and Daqiaotou Station (O12). Despite the different travel directions, the $\mathrm{PM}_{10}$ and $\mathrm{PM}_{2.5}$ levels inside the metro train carriages showed similar variation trends on both $\mathrm{O}(\mathrm{A})$ and $\mathrm{O}(\mathrm{B})$, especially between Nanshijiao Station (O01) and Daqiaotou Station (O12). For the direction from Nanshijiao Station (O01) to Daqiaotou Station (O12), the highest $\mathrm{PM}_{10}$ and $\mathrm{PM}_{2.5}$ levels could usually be observed close to Guting Station (O05). However, the highest $\mathrm{PM}_{10}$ and $\mathrm{PM}_{2.5}$ levels could be observed at around Yongan Market Station (O03) in the opposite travel direction from Daqiaotou Station (O12) to Nanshijiao Station (O01). Limited by the space available in underground, the trains run on different floor tracks between Nanshijiao Station (O01) and Dongmen Station (O06) in different travel directions. That is why the highest $\mathrm{PM}$ levels were observed at different locations on $\mathrm{O}$ in different travel directions. Furthermore, the lowest $\mathrm{PM}_{10}$ and $\mathrm{PM}_{2.5}$ levels always occurred at around the starting station. These measurement results indicate that the variations in $\mathrm{PM}_{10}$ and $\mathrm{PM}_{2.5}$ levels inside the metro train carriages on $\mathrm{O}$ (A) and $\mathrm{O}$ (B) were related to the surrounding conditions of the trains, such as their journey in different travel directions. Compared with the $\mathrm{PM}_{10}$ and $\mathrm{PM}_{2.5}$ levels, the PN level showed less variation. The variations in the particle mass size distributions inside metro train 
(a)
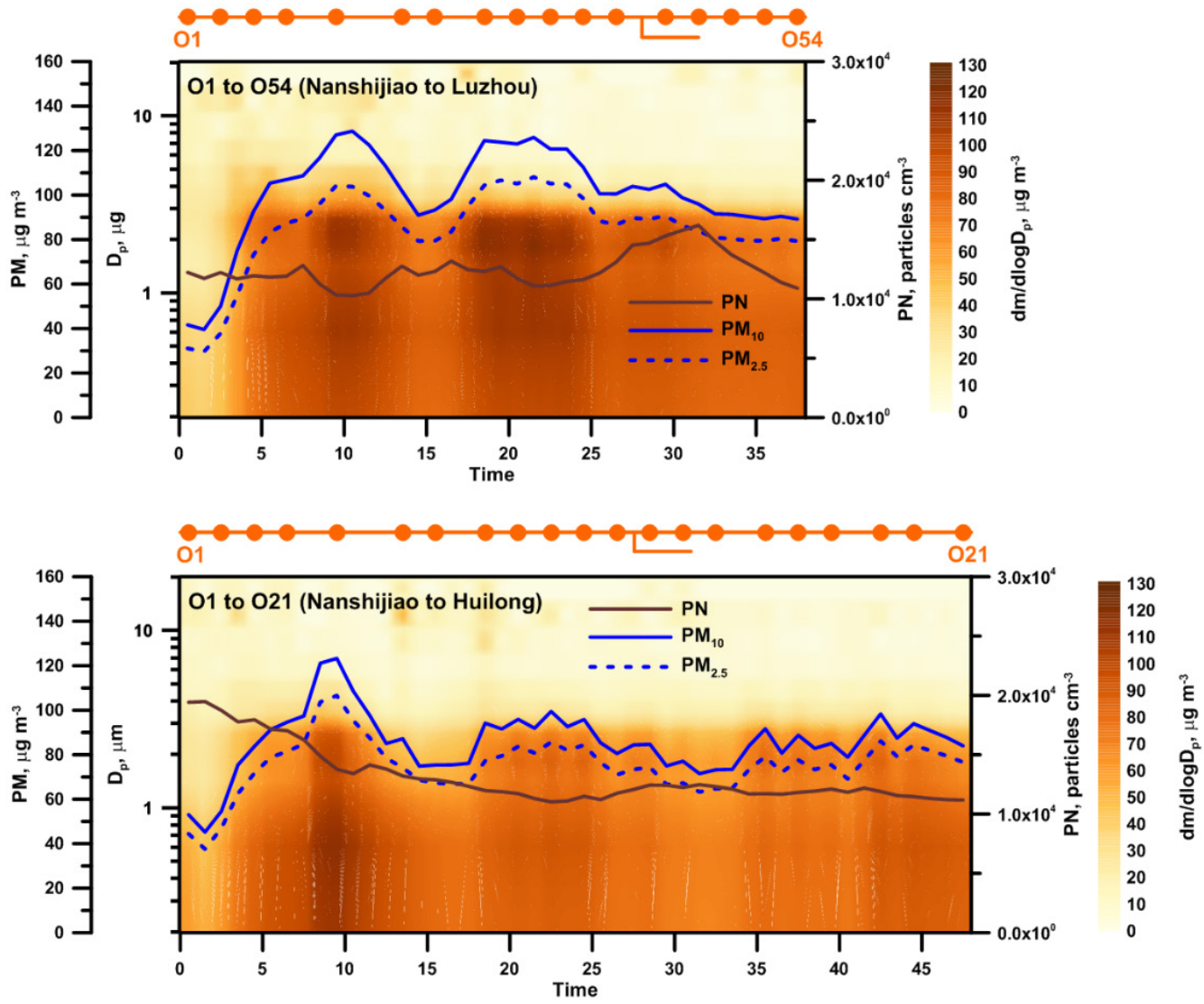

(b)
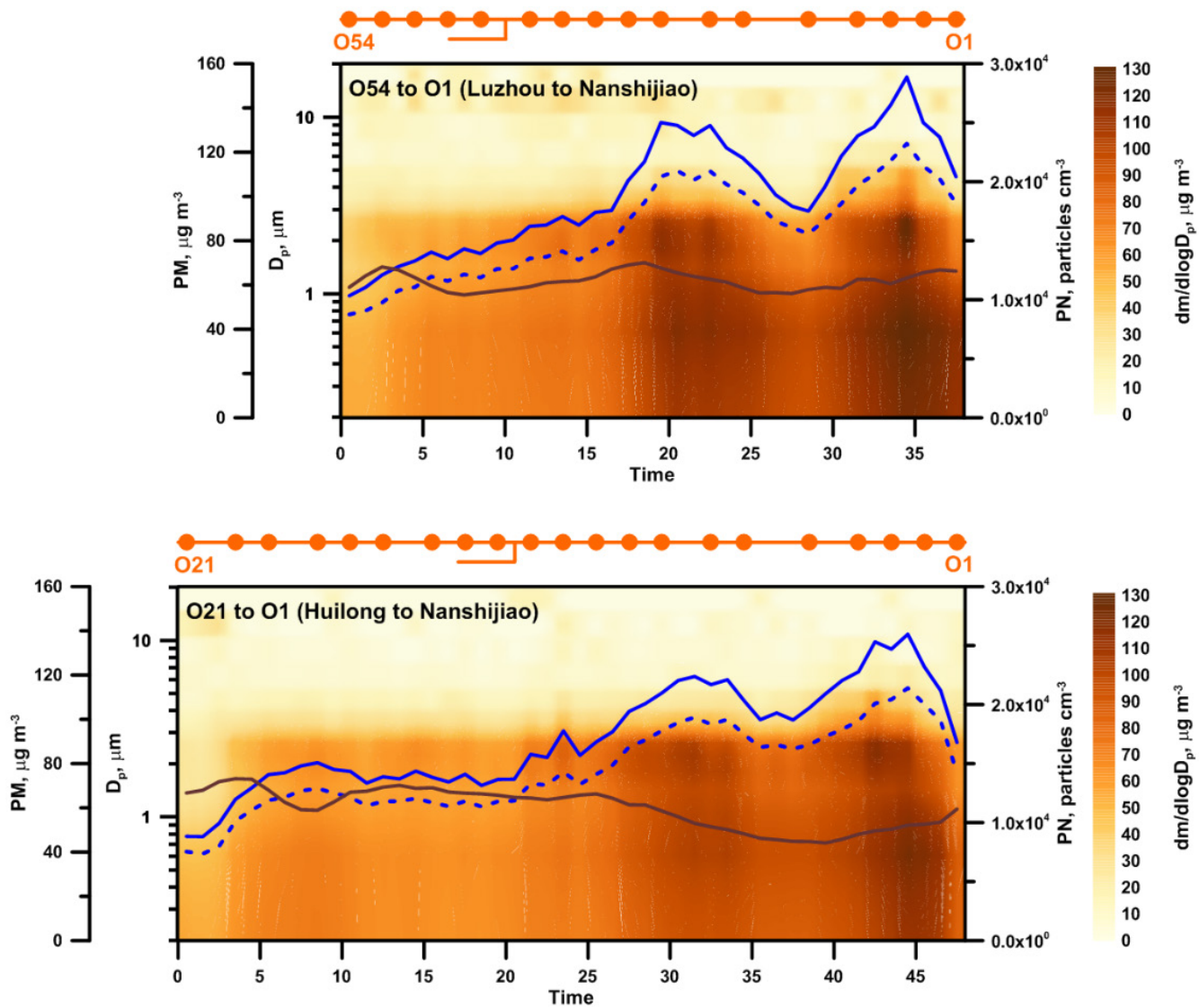

Fig. 10 Variation trends of $\mathrm{PM}_{10}, \mathrm{PM}_{2.5}$, and $\mathrm{PN}$ concentrations and particle mass size distributions inside metro train carriages on $\mathrm{O}$ from (a) $\mathrm{O} 01$ to $\mathrm{O} 21$ (or O54) and (b) $\mathrm{O} 21$ (or O54) to O01. 
carriages were also associated with change in air quality conditions in the underground tunnel. Two remarkable modes were observed in the mass size distribution patterns: approximately 0.5 and $2.1 \mu \mathrm{m}$.

The variation trends of $\mathrm{PM}_{10}, \mathrm{PM}_{2.5}$, and $\mathrm{PN}$ concentrations and particle mass size distributions inside the metro train carriages on $\mathrm{G}$ and $\mathrm{BL}$ are shown in Figs. S1 and S2, respectively, indicating that they are similar to those on $\mathrm{O}(\mathrm{A})$ and $\mathrm{O}(\mathrm{B})$. The variation trends of $\mathrm{PM}_{10}, \mathrm{PM}_{2.5}$, and $\mathrm{PN}$ concentrations inside the metro train carriages were irregular and related to the surrounding conditions of the trains, such as their journey, the design of the tunnel and station, and in different travel directions, where the PM levels on the platforms along the whole metro line were different.

\section{CONCLUSIONS}

This study provides information on the $\mathrm{PM}_{10}, \mathrm{PM}_{2.5}, \mathrm{PN}$, and $\mathrm{CO}_{2}$ concentrations and particle mass size distributions inside metro train carriages on seven selected routes in the Taipei MRT system. The $\mathrm{CO}_{2}$ level was observed to be associated with ridership; hence, increasing the air change rate inside metro carriages may reduce exposure to $\mathrm{CO}_{2}$ during rush hours. Additionally, the PM levels and particle mass size distributions were remarkably affected by the immediate surroundings of the train, such as whether it was journeying through underground tunnels or on groundlevel tracks as well as its direction of travel. The PM levels inside the carriages of trains running through underground tunnels were significantly higher-by approximately 3-10 times - than those of trains running on ground-level tracks, indicating that the levels inside carriages on ground-level routes were affected by outdoor ambient air conditions. However, the levels inside the carriages on underground routes were highly influenced by the tunnel conditions. Moreover, the variation trends of the PM levels depended on the direction of travel. Since the $\mathrm{PM}_{2.5}$ level exceeded $35 \mu \mathrm{g} \mathrm{m}^{-3}$ on the underground routes, the cars should be equipped with a higher-efficiency filter in order to protect commuters. In contrast to the PM, the PN level inside the metro train carriages was significantly lower on underground routes than ground-level routes. In both environments, the PN level inside the carriages was usually lower than that of the outdoor ambient air. The worst air quality inside the carriages was directly induced by poor tunnel conditions when metro trains were traveling through underground tunnels. Therefore, improving the air quality in the underground tunnels is another critical issue for the Taipei MRT authority. Furthermore, the particle mass size distributions inside the metro train carriages exhibited a clear triple-mode pattern. However, those for the groundlevel and underground routes differed considerably due to different external sources for the particles.

\section{ACKNOWLEDGMENTS}

The authors would like to thank the Ministry of Science and Technology of the Republic of China, Taiwan, for financially supporting this research under Contract No. MOST 104-2632-E-131-001 and MOST 105-2632-E-131001 .

\section{SUPPLEMENTARY MATERIAL}

Supplementary data associated with this article can be found in the online version at http://www.aaqr.org.

\section{REFERENCES}

Abbasi, S., Jansson, A., Sellgren, U, and Olofsson, U. (2013). Particle emissions from rail traffic: A literature review. Crit. Rev. Environ. Sci. Technol. 43: 25112544.

Bachoual, R., Boczkowski, J., Goven, D., Amara, N., Tabet, L., On, D., Leçon-Malas, V., Aubier, M. and Lanone, S. (2007). Biological effects of particles from the Paris subway system. Chem. Res. Toxicol. 20: 14261433.

Cartenì, A., Cascetta, F. and Campana, S. (2015). Underground and ground-level particulate matter concentrations in an Italian metro system. Atmos. Environ. 101: 328-337.

Cartenì, A. and Cascetta, F. (2018). Particulate matter concentrations in a high-quality rubber-tyred metro system: The case study of Turin in Italy. Int. J. Environ. Sci. Technol. 15: 1921-1930.

Chan, C.C., Spengler, J.D., Özkaynak, H. and Lefkopoulou, M. (1991). Commuter exposures to VOCs in Boston, Massachusetts. J. Air Waste Manage. Assoc. 41: 15941600.

Chen, Y.Y., Lu, C.Y., Chen, P.C., Mao, I.F. and Chen, M.L. (2017). Analysis of aerosol composition and assessment of tunnel washing performance within a mass rapid transit system in Taiwan. Aerosol Air Qual. Res. 17: 1527-1538.

Cheng, Y.H. (2008). Comparison of the TSI model 8520 and Grimm series 1.108 portable aerosol instruments used to monitor particulate matter in an iron foundry. $J$. Occup. Environ. Hyg. 5: 157-168.

Cheng, Y.H. and Yan, J.W. (2011). Comparisons of particulate matter, $\mathrm{CO}$, and $\mathrm{CO}_{2}$ levels in underground and ground-level stations in the Taipei mass rapid transit system. Atmos. Environ. 45: 4882-4891.

Cheng, Y.H., Chang, H.P. and Hsieh, C.J. (2011). Shortterm exposure to $\mathrm{PM}_{10}, \mathrm{PM}_{2.5}$, ultrafine particles and $\mathrm{CO}_{2}$ for passengers at an intercity bus terminal. Atmos. Environ. 45: 2034-2042.

Cheng, Y.H., Liu, Z.S. and Yan, J.W. (2012). Comparisons of $\mathrm{PM}_{10}, \mathrm{PM}_{2.5}$, particle number, and $\mathrm{CO}_{2}$ levels inside metro trains traveling in underground tunnels and on elevated tracks. Aerosol Air Qual. Res. 12: 879-891.

Cusack, M., Talbot, N., Ondráček, J., Minguillón, M. C., Martins, V., Klouda, K., Schwarz, J. and Ždímal, V. (2015). Variability of aerosols and chemical composition of $\mathrm{PM}_{10}, \mathrm{PM}_{2.5}$ and $\mathrm{PM}_{1}$ on a platform of the Prague underground metro. Atmos. Environ. 118: 176-183.

Jung, H.J., Kim, B.W., Malek, M.A., Koo, Y.S., Jung, 
J.H., Son, Y.S., Kim, J.C., Kim, H.K. and Ro, C.U. (2012). Chemical speciation of size-segregated floor dusts and airborne magnetic particles collected at underground subway stations in Seoul, Korea. J. Hazard. Mater. 213: 331-340.

Kam, W., Cheung, K., Daher, N. and Sioutas, C. (2011). Particulate matter (PM) concentrations in underground and ground-level rail systems of the Los Angeles Metro. Atmos. Environ. 45: 1506-1516.

Karlsson, H.L., Ljungman, A.G., Lindbom, J. and Möller, L. (2006). Comparison of genotoxic and inflammatory effects of particles generated by wood combustion, a road simulator and collected from street and subway. Toxicol. Lett. 165: 203-211.

Karlsson, H.L., Holgersson, Å. and Möller, L. (2008). Mechanisms related to the genotoxicity of particles in the subway and from other sources. Chem. Res. Toxicol. 21: 726-731.

Martins, V., Moreno, T., Minguillon, M.C., Amato, F., de Miguel, E., Capdevila, M. and Querol, X. (2015). Exposure to airborne particulate matter in the subway system. Sci. Total Environ. 511: 711-722.

Moreno, T., Martins, V., Querol, X., Jones, T., BéruBé, K., Minguillón, M.C., Amato, F., Capdevila, M., Miguel, E., Centelles, S. and Gibbons, W. (2015). A new look at inhalable metalliferous airborne particles on rail subway platforms. Sci. Total Environ. 505: 367-375.

Moreno, T., Pérez, N., Reche, C., Martins, V., De Miguel, E., Capdevila, M., Centelles, S., Minguillón, M.C., Amato, F., Alastuey, A., Querol, X. and Gibbons, W. (2014). Subway platform air quality: Assessing the influences of tunnel ventilation, train piston effect and station design. Atmos. Environ. 92: 461-468.

Nieuwenhuijsen, M.J., Gómez-Perales, J.E. and Colvile, R.N. (2007). Levels of particulate air pollution, its elemental composition, determinants and health effects in metro systems. Atmos. Environ. 41: 7995-8006.

Park, D.U. and Ha, K.C. (2008). Characteristics of $\mathrm{PM}_{10}$, $\mathrm{PM}_{2.5}, \mathrm{CO}_{2}$ and $\mathrm{CO}$ monitored in interiors and platforms of subway train in Seoul, Korea. Environ. Int. 34: 629634.

Querol, X., Moreno, T., Karanasiou, A., Reche, C., Alastuey, A., Viana, M., Font, O., Gil, J., de Miguel, E. and Capdevila, M. (2012). Variability of levels and composition of $\mathrm{PM}_{10}$ and $\mathrm{PM}_{2.5}$ in the Barcelona metro system. Atmos. Chem. Phys. 12: 5055-5076.
Şahin, Ü.A., Onat, B., Stakeeva, B., Ceran, T. and Karim, P. (2012). $\mathrm{PM}_{10}$ concentrations and the size distribution of $\mathrm{Cu}$ and Fe-containing particles in Istanbul's subway system. Transp. Res. Part D 17: 48-53.

Salma, I., Weidinger, T. and Maenhaut, W. (2007). Timeresolved mass concentration, composition and sources of aerosol particles in a metropolitan underground railway station. Atmos. Environ. 41: 8391-8405.

Salma, I., Pósfai, M., Kovács, K., Kuzmann, E., Homonnay, Z. and Posta, J. (2009). Properties and sources of individual particles and some chemical species in the aerosol of a metropolitan underground railway station. Atmos. Environ. 43: 3460-3466.

Seaton, A., Cherrie, J., Dennekamp, M., Donaldson, K., Hurley, J.F. and Tran, C.L. (2005). The London Underground: Dust and hazards to health. Occup. Environ. Med. 62: 355-362.

Sousan, S., Koehler, K., Hallett, L. and Peters, T.M. (2016). Evaluation of the Alphasense optical particle counter (OPC-N2) and Grimm portable aerosol spectrometer (PAS-1.108). Aerosol Sci. Technol. 50: 1352-1365.

Steenhof, M., Gosens, I., Strak, M., Godri, K.J., Hoek, G., Cassee, F.R., Mudway, I.S., Kelly, F.I., Harrison, R.M., Lebret, E., Brunekreef, B., Janssen, N.A.H. and Pieters, R.H.H. (2011). In vitro toxicity of particulate matter (PM) collected at different sites in the Netherlands is associated with PM composition, size fraction and oxidative potential-the RAPTES project. Part. Fibre Toxicol. 8: 26.

TRTC (2017). Taipei Rapid Transit Corporation Annual Report 2016, Taipei, Taiwan.

Woo, S.H., Kim, J.B., Bae, G.N., Hwang, M.S., Tahk, G.H., Yoon, H.H. and Yook, S.J. (2018). Investigation of diurnal pattern of generation and resuspension of particles induced by moving subway trains in an underground tunnel. Aerosol Air Qual. Res. 18: 2240-2252.

Xu, B., Yu, X., Gu, H., Miao, B., Wang, M. and Huang, H. (2016). Commuters' exposure to $\mathrm{PM}_{2.5}$ and $\mathrm{CO}_{2}$ in metro carriages of Shanghai metro system. Transp. Res. Part D 47:162-170.

Received for review, September 12, 2018 Revised, February 11, 2019 Accepted, March 13, 2019 